\title{
Clinical factors affecting the translucency of monolithic Y-TZP ceramics
}

Pekkan, Gürel ; Özcan, Mutlu ; Subaşı, Meryem Gülce

\begin{abstract}
The use of monolithic yttria-stabilized tetragonal zirconia polycrystal (Y-TZP) ceramics in aesthetically critical regions is questionable because of the insufficient translucency and opacity of the restorations. Intrinsic (manufacturing process) and extrinsic factors (laboratory procedures and clinical factors) can affect the translucency of monolithic zirconia. In this narrative review, the clinical factors (thickness, cementation type, colour of the monolithic zirconia, surface finishing methods and wear, dental background, cement colour, low temperature degradation) affecting the translucency of monolithic Y-TZP ceramics were reported.
\end{abstract}

DOI: https://doi.org/10.1007/s10266-019-00446-2

Posted at the Zurich Open Repository and Archive, University of Zurich

ZORA URL: https://doi.org/10.5167/uzh-198264

Journal Article

Accepted Version

Originally published at:

Pekkan, Gürel; Özcan, Mutlu; Subaşı, Meryem Gülce (2020). Clinical factors affecting the translucency of monolithic Y-TZP ceramics. Odontology / the Society of the Nippon Dental University, 108(4):526-531.

DOI: https://doi.org/10.1007/s10266-019-00446-2 


\section{Clinical factors affecting the translucency of monolithic Y-TZP ceramics}

Gürel Pekkan ${ }^{\mathrm{a}}$, Mutlu Özcan ${ }^{\mathrm{b}}$, Meryem Gülce Subaşı ${ }^{\text {a }}$

a Tekirdag Namik Kemal University, Faculty of Dentistry, Department of Prosthodontics, Tekirdag, Turkey.

bUniversity of Zürich, Dental Materials Unit, Center for Dental and Oral Medicine, Clinic for Fixed and Removable Prosthodontics and Dental Materials Science, Plattenstrasse 11, CH-8032, Zurich, Switzerland.

Short title: Clinical factors affecting translucency of Y-TZP

*Corresponding author: Gürel Pekkan, Tekirdag Namik Kemal University, Faculty of Dentistry, Department of Prosthodontics, Degirmenalti Yerleskesi, 59030, Suleymanpasa, Tekirdag, Turkey. Tel: +90 282250 6301, E-mail address: gurelp@gmail.com, gpekkan@nku.edu.tr 


\title{
Clinical factors affecting the translucency of monolithic Y-TZP ceramics
}

\begin{abstract}
The use of monolithic yttria-stabilized tetragonal zirconia polycrystal (Y-TZP) ceramics in aesthetically critical regions is questionable because of the insufficient translucency and opacity of the restorations. Intrinsic (manufacturing process) and extrinsic factors (laboratory procedures and clinical factors) can affect the translucency of monolithic zirconia. In this narrative review, the clinical factors (thickness, cementation type, colour of the monolithic zirconia, surface finishing methods and wear, dental background, cement colour, low temperature degradation) affecting the translucency of monolithic Y-TZP ceramics was reported.
\end{abstract}

Keywords: Zirconia; Monolithic; Translucency; Colour; Wear 


\section{Introduction}

In recent years monolithic yttria-stabilized tetragonal zirconia polycrystal (Y-TZP) restorations have been produced to eradicate the risk of veneering porcelain chipping or fracture [1]. They have become popular due to their high flexural and mechanical strength, minimal wear on opposing teeth, shortened time of fabrication (clinical and laboratory), no need of veneering porcelain, decreased cost [1-6], and allowing production of prostheses with significantly reduced thickness such as $0.5 \mathrm{~mm}$ [7-9]. The other clinical advantage of full contour monolithic zirconia restorations is that of alternatively they can be used either in a hybrid design such as the buccal and lingual aspect of the monolithic restoration can also be veneered to enhance an aesthetic outcome [10].

Monolithic Y-TZP restorations are fabricated from computer aided design/computer aided manufacturing (CAD/CAM) using either partially or fully sintered blocks [11]. They can be finished either polishing or glazing [12].

Colour and translucency are two factors affecting the aesthetics of all-ceramic restorations, which the latter is of primary importance in aesthetics [13]. It is related to the transmission and adsorption of light. In a dental restoration, if only a minor part of the light is scattered and most is transmitted diffusely, the material will appear translucent [14].

In prosthetic dentistry in order to achieve aesthetic appearance, the optical behavior of a translucent monolithic Y-TZP needs to be similar to that of the natural tooth [15]. It was reported that intrinsic (material microstructural and processing properties) and extrinsic factors (laboratory and clinical factors) can affect the translucency of monolithic zirconia restoration [16]. Although intrinsic parameters can not be manipulated by the clinician, extrinsic factors can be manipulated by the clinician. Clinical parameters, such as thickness [10,14,17-21], cementation type [22], colour of Y-TZP ceramics [5,17,19,23-28], surface finishing protocols [14,29,30], the use of Y-TZP ceramics as implant abutments [31-34], dental background [35-38], cement colour [39,40], and low temperature degradation [10,41-46] which are in the category of extrinsic factors should also be taken into consideration when evaluating the translucency of monolithic Y-TZP ceramics. This narrative review gives knowledge about the clinical factors that affect the translucency of monolithic Y-TZP ceramics which can be effective in clinical success of these ceramics.

\section{Clinical factors affecting the success of monolithic Y-TZP ceramics}

\subsection{Thickness}

Thickness of monolithic Y-TZP ceramics is important for the amount of light passing through the restoration [47]. In the literature, the effect of different thicknesses on the optical properties of monolithic zirconia ceramics [10,14,17-21], and multilayered monolithic zirconia [48] were evaluated. All of these studies [10,14,17-21,48] outlined that thickness inversely affected the zirconia translucency data. Therefore, based on the results of these studies $[10,14,17-21,40,48,49]$, the restorations with the monolithic Y-TZP ceramics can be thinner as $0.5-0.9 \mathrm{~mm}$ taking into account that not compromising the strength and color of the material. In addition, making the restorations thinner in order to create more translucent restoration should be done with attention, because the masking ability of the zirconia of coloured teeth should also be taken into account and the thickness balance should be considered according to the specific case. 


\subsection{Cementation type}

Cementation of monolithic Y-TZP ceramic restorations can be done with traditional cements (glass ionomers, phosphate or polycarboxylate cements) or resin cements [50]. It was reported that [22] cementation type affected the translucency of monolithic zirconia restorations and resin cements/resin modified glass-ionomer cements presented higher translucency values than conventional glass-ionomer cements.

\subsection{Colour of the monolithic Y-TZP ceramics}

The clinical colour matching with the tooth restored or the neighboring teeth using monolithic Y-TZP ceramics is challenging. To overcome this issue, manufacturers have produced preshaded monolithic zirconia ceramics, externally shaded monolithic zirconia, or multilayered monolithic zirconia ceramics with different translucency levels such as high, super, and ultra translucency [38]. Preshaded zirconia blanks are manufactured adding colourant pigments (metal oxides) $\left(\mathrm{Fe}_{2} \mathrm{O}_{3}, \mathrm{CeO}_{2}\right.$, and $\left.\mathrm{Bi}_{2} \mathrm{O}_{3}\right)$ to zirconia powder through manufacturing process [26]. They are mostly available according to VITA classical shades [38].

Externally shaded zirconia can be obtained by immersing non-sintered or pre-sintered uncoloured zirconia in colour liquids [26], or using colour liners over sintered zirconia [26,51]. In immersion technique, type and shade of colour liquid, and the dipping time should be considered [52]. Manufacturers have also generated different shades (VITA classical or VITA 3-D Master) for colour liquids $[26,53]$.

Recently, highly translucent multi-layered monolithic zirconia ceramics have been proposed as a solution for the colour improvement of monolithic zirconia restorations $[28,54,55]$. They have derived from the concept of production of zirconia blocks containing different layers with various translucencies and shades. Ueda et al. [28] investigated the light transmittance of different layers of these material and found significantly different light transmission mean values among four layers.

It was reported that colouring may influence the optical property of zirconia by producing crystallographic and microstructural alterations in the material $[5,26]$. Suleiman et al. [5] examined the effects of external staining on translucency parameter data of fully stabilized zirconia versus partially stabilized zirconia and stated a significant decline in the translucency of fully stabilized zirconia after staining. They based this finding to the larger grains and grain boundaries of fully stabilized zirconia that may have led to an increase in colouring liquid intake, therefore resulting in reduced translucency. On the other hand, Kurtulmuş-Y1lmaz et al. 2014 [24] reported that external colouring technique did not have a significant effect on translucency of zirconia cores. Sen et al. [25] indicated that translucency of monolithic zirconia was impressed by material type, however not affected by the colouring technique (pre or ext). Some studies [17,27] reported that for the same zirconia material, shading technique (ext or pre) affected the translucency of monolithic zirconia. Alp et al. [17] reported that at thickness of 1, 1,5 and 2 mm, and Subasi et al. [27] reported that at a thickness of $1,5 \mathrm{~mm}$ externally shaded zirconia showed significantly higher translucency value than preshaded monolithic zirconia. Other studies [24,56] reported significant differences among the translucencies of differently pre-shaded monolithic zirconia materials. 
To sum up, all of these studies [5,17,24-27,56] results showed that translucency of zirconia is dependent on the material type. Therefore, in clinical practice to obtain better translucency the selection of shading technique (external or preshaded) is dependent on the selection of the zirconia type.

\subsection{Surface finishing methods and Wear}

Before delivering the restoration to the patient, final surface state of monolithic Y-TZP ceramics is of great importance, because it might affect the translucency, tribological, and metastability behavior of the material. The manufacturers of monolithic zirconia recommend either polish or glaze treatments for final surface finishing of these restorations before the cementation of the restoration to the patient's tooth. Therefore, these surface treatments effect on translucency should be considered.

Studies [14,29,30] declared no differences in translucency between polished and unpolished monolithic zirconia ceramic surfaces. In addition, Kim et al. [30] reported that there was no difference in translucency parameter data between polished and glazed of externally shaded monolithic zirconia, while glazing reduced opalescence.

Surface treatments may have an impact on tribological behaviors. Some studies [9,57-60] reported that against enamel, polished monolithic zirconia presented less wear than glazed monolithic zirconia. In addition, Zurek et al. [61] reported that against ceramic, glazed-polished monolithic zirconia surface presented lower volume loss than monolithic glazed zirconia surface. Based on these studies results [9,57-61], the glaze layer over the Y-TZP restorations may be worn in time and the restoration would come to contact with the opposing tooth or restoration. Therefore, in this situatation the surface state of the monolithic Y-TZP ceramic becomes more important for metastability of the material.

Surface treatments or wear can also affect the metastability property (phase transformation) of monolithic Y-TZP. Before cementation the restoration inner surface can be adjusted with burs or can be air abraded before adhesive cementation $[62,63]$. It is well known that, the grinding and sandblasting of zirconia materials lead to surface phase transformation (tetragonal to monoclinic), and development of compressive stresses [9]. Chair-side polishing eliminates this thin monoclinic phase to a certain degree but deep defects and scratches that are created with coarse burs may remain on the restoration surface. Furthermore, after polishing, surface stress state of the material would lead to sensitivity to low temperature degradation (LTD) by enhancing monoclinic phase nucleation around residual scratches [64]. Therefore, it is of great importance to carefully polishing the surface of monolithic Y-TZP restoration if grinding adjustments are made in the laboratory or before delivering the restoration to the patient. On the other side, heat treatment or final glaze firing following grinding and sandblasting was pointed out to reverse the phase transformation (monoclinic to tetragonal) and eradicate compressive stresses [64,65]. Therefore, in clinical practice, after adjustements in the laboratory, the restorations can be fired as reported by previous studies $[64,65]$.

\subsection{The use of monolithic Y-TZP ceramics on implants}

Monolithic Y-TZP ceramics are also used in fabrication of implant abutments as single- or multi-unit cemented restorations. However, it is not preferred due to limited fracture strength of the monolithic Y-TZP material. The main problems are associated with design and processing with custom CAD/CAM abutments. Microcracking after machining and cubic phase at abutment 
surfaces cause failures of the monolithic Y-TZP ceramic restorations [1]. Therefore, titanium based hybrid abutments are used instead of using monolithic material.

In case of implant abutments, translucency of the material is the issue, because the material thickness has to be much more than the tooth supported restorations. Furthermore, the translucency of the restoration may be affected from the abutment type (titanium or zirconia) [31-34].

\subsection{Dental Background}

In a dental restoration, a background (enamel or dentin) is the deepest layer that light may undergo. The background condition is based on the translucency of ceramics. As the ceramic translucency increases, the background effect increases [66].

Monolithic zirconia ceramics are more translucent than framework zirconia ceramics and less translucent than feldspathic and glass ceramics $[18,20,21,47,67]$. Considering the background condition, most of the manufacturers have manufactured zirconia ceramic brands with different levels of masking ability on coloured backgrounds (light, medium, dark shaded, metal) [38].

In clinical practice, to compensate for the background condition, several solutions are recommended: such as using backgrounds with colour close to main colour [36,37], masking backgrounds with proper cements [35], or rising the zirconia thickness $[37,39,40,68]$.

\subsection{Cement Colour}

Regarding optical characteristics, cements are classified into shaded, bleached, opaque, and transparent [69,70]. Opaque cements create a lighter shade, while transparent cements create a darker shade [71]. If the cement is more transparent, the background effect becomes more critical [35]. If the ceramic restoration is more translucent, the cement becomes more critical [72].

Opaque cements may be used for dark/metal/discoloured backgrounds to mask them, but then an increase in ceramic thickness is needed to compensate for the cement colour. In addition, tooth-coloured cements may be the choice for tooth-coloured backgrounds to create colour consistency between cement, background, and ceramic according to target colour. This fact profitably eradicates the need for increasing the ceramic thickness [38].

Depending on the cement and background conditions, the minimum zirconia thickness may be in the range of 0.9-1.6 mm [39]. When tooth-coloured backgrounds and cements are used, zirconia thickness may be declined to the minimum such as $0.5 \mathrm{~mm}$. When discoloured/metal backgrounds and opaque cements are preferred, zirconia thickness should be increased. Finally, a background-cement-ceramic colour consistency is recommended to increase the translucency of monolithic zirconia restorations $[39,40]$.

\subsection{Low Temperature Degradation (LTD)}

LTD is another important factor that affects the clinical success of monolithic zirconia restorations. LTD is a phenomenon that existence of water and low temperature over time, a tetragonal-monoclinic ( $\mathrm{t}-\mathrm{m})$ phase transformation is provoked at zirconia ceramic surface [73]. This ends in a volume enlargement of grains, which causes surface roughening, microcracking, and possibly loss of strength. Regarding different monolithic zirconia ceramics, studies [41,43-46] showed that translucency is affected by the 
aging process. Some of them $[41,43,45,46]$ reported that translucency was material dependent and decreased after aging. On the other hand Kim et al. [44] reported an increase in translucency after aging.

The optical properties of monolithic zirconia materials are influenced by their microstructure. Due to aging or mechanical stress crystal structure of monolithic Y-TZP may alter from tetragonal to monoclinic [74,75]. Monoclinic and tetragonal crystals have distinct optical properties [76], and monoclinic zirconia crystals scatter light more than other crystals [77]. Therefore, change in translucency after aging is associated with transformation of zirconia from tetragonal to monoclinic phase [43-45].

Harada et al. [10] reported that the reduction of transformation from tetragonal to monoclinic phase after aging may be produced by using translucent zirconia that contains reduced $\mathrm{Al}_{2} \mathrm{O}_{3}$ content to develop light transmittance and a raise in $\mathrm{Y}_{2} \mathrm{O}_{3}$ content to decrease LTD. Therefore, in clinical practice to minimize the effect of LTD, material selection of monolithic zirconia is important. In recent years, partially cubic monolithic high translucency or multi-layered zirconia was manufactured [42]. Camposilvan et al. [42] reported that these materials may be more translucent than standard 3Y-TZP and do not affect from in vitro hydrothermal degradation, however their toughness and strength are effectively lower. Thus, manipulation and crown preparation should be done carefully, and thin walls and sharp edges should be avoided as much as possible. In addition, they could not be used in the mouth where high mechanical stresses are exist.

\section{Conclusions}

The translucency of the monolithic zirconia is a complex phenomenon because different parameters such as intrinsic (manufacturing process) and extrinsic factors (laboratory procedures and clinical factors) affect its translucency. Within all of these factors, clinical factors (thickness, cementation type, colour of monolithic Y-TZP, surface finishing methods, the use of monolithic Y-TZP ceramics as implant abutments, background colour, cementation colour, LTD) can be controlled by dentists in clinical practice. Because of each clinical factor affects the other factor, to obtain clinical success in performing translucency of monolithic zirconia, all of these parameters should be evaluated together.

\section{Clinical Relevance}

In clinical practice to obtain pleasing aesthetics regarding translucency, clinicians should firstly select the monolithic zirconia type depending on the case. Other clinical factors such as cementation type, background colour, cement colour and thickness should be evaluated together depending on the selection of the monolithic zirconia type. In addition to lower the effect of LTD, final surface finishing of monolithic zirconia should be performed carefully to minimize the phase transformation.

\section{Acknowledgements}

\section{Conflict of interest}

The authors did not have any commercial interest in any of the materials used in this study. 


\section{References}

1. Denry I, Kelly JR. Emerging ceramic-based materials for dentistry. J Dent Res. 2014; 93:1235-42.

2. Ghodsi S, Jafarian Z. A review on translucent zirconia. Eur J Prosthodont Restor Dent 2018; 26:62-74.

3. Ebeid K, Wille S, Hamdy A, Salah T, El-Etreby A, Kern M. Effect of changes in sintering parameters on monolithic translucent zirconia. Dent Mater. 2014; 30:e419-24.

4. Griffin JD Jr. Tooth in a bag: same-day monolithic zirconia crown. Dent Today. 2013; 32:124, 126-31.

5. Sulaiman TA, Abdulmajeed AA, Donovan TE, Valittu PK, Närhi TO, Lassila LV. The effect of staining and vacuum sintering on optical and mechanical properties of partially and fully stabilized monolithic zirconia. Dent Mater J. 2015; 34:605-10.

6. Sulaiman TA, Abdulmajeed AA, Shahramian K, Lassila L. Effect of different treatments on the flexural strength of fully versus partially stabilized monolithic zirconia. J Prosthet Dent. 2017; 118:216-20.

7. Rinke S, Fischer C. Range of indications for translucent zirconia modifications: clinical and technical aspects. Quintessence Int. 2013; 44:557-66.

8. Sripetchdanond J, Leevailoj C. Wear of human enamel opposing monolithic zirconia, glass ceramic, and composite resin: an in vitro study. J Prosthet Dent. 2014; 112:1141-50.

9. Stawarcyzk B, Özcan M, Schmutz F, Trottmann A, Roos M, Hämmerle CH. Two-body wear of monolithic, veneered and glazed zirconia and their corresponding enamel antagonists. Acta Odontol Scand. 2013; 71:102-12.

10. Harada K, Raigrodski AJ, Chung KH, Flinn BD, Dogan S, Mancl LA. A comparative evaluation of the translucency of zirconias and lithium disilicate for monolithic restorations. J Prosthet Dent. 2016; 116:257-63.

11. Tinschert J, Natt G, Hassenpflug S, Spiekermann H. Status of current CAD/CAM technology in dental medicine. Int J Comput Dent. 2004; 7:25-45.

12. Hmaidouch R, Müller WD, Lauer HC, Weigl P. Surface roughness of zirconia for full-contour crowns after clinically simulated grinding and polishing. Int J Oral Sci. 2014; 61:241-6.

13. O'Keefe KL, Pease PL, Herrin HK. Variables affecting the spectral transmittance of light through porcelain veneer samples. J Prosthet Dent. 1991; 66:434-8.

14. Sulaiman TA, Abdulmajeed AA, Donovan TE, Ritter AV, Valittu PK, Närhi TO, Lassila LV. Optical properties and light irradiance of monolithic zirconia at variable thicknesses. Dent Mater. 2015; 31:1180-7.

15. Juntavee N, Attashu S. Effect of sintering process on color parameters of nano-sized yttria partially stabilized tetragonal monolithic zirconia. J Clin Exp Dent. 2018; 10:e794-e804.

16. Shahmiri R, Standard OC, Hart JN, Sorrell CC. Optical properties of zirconia ceramics for esthetic dental restorations: A systematic review. J Prosthet Dent. 2018; 119:36-46. 
17. Alp G, Subaşı MG, Seghi RR, Johnston WM, Yilmaz B. Effect of shading technique and thickness on color stability and translucency of new generation translucent zirconia. J Dent. 2018; 73:19-23.

18. Ilie N, Stawarczyk B. Quantification of the amount of blue light passing through monolithic zirconia with respect to thickness and polymerization conditions. J Prosthet Dent. 2015; 113:114-121.

19. Kim HK, Kim SH, Lee JB, Han JS, Yeo IS, Ha SR. Effect of the amount of thickness reduction on color and translucency of dental monolithic zirconia ceramics. J Adv Prosthodont. 2016; 8:37-42.

20. Subaşı MG, Alp G, Johnston WM, Yilmaz B. Effect of thickness on optical properties of monolithic CAD-CAM ceramics. J Dent. 2018; 71:38-42.

21. Wang F, Takahashi H, Iwasaki N. Translucency of dental ceramics with different thicknesses. J Prosthet Dent. 2013; 110:14-20.

22. Malkondu O, Tinastepe N, Kazazoglu E. Influence of type of cement on the color and translucency of monolithic zirconia. J Prosthet Dent. 2016; 116:902-8.

23. Kim HK, Kim SH. Effect of the number of coloring liquid applications on the optical properties of monolithic zirconia. Dent Mater. 2014; 30:e229-37.

24. Kurtulmus-Yilmaz S, Ulusoy M. Comparison of the translucency of shaded zirconia all-ceramic systems. J Adv Prosthodont. 2014; 6:415-22.

25. Sen N, Sermet IB, Cinar S. Effect of coloring and sintering on the translucency and biaxial strength of monolithic zirconia. J Prosthet Dent. 2018; 119:308.

26. Shah K, Holloway JA, Denry IL. Effect of coloring with various metal oxides on the microstructure, color, and flexural strength of 3Y-TZP. J Biomed Mater Res B Appl Biomater. 2008; 87:329-37.

27. Subaşı MG, Alp G, Johnston WM, Yilmaz B. Effects of fabrication and shading technique on the color and translucency of new-generation translucent zirconia after coffee thermocycling. J Prosthet Dent. 2018; 120:603-8.

28. Ueda K, Güth JF, Erdelt K, Stimmelmayr M, Kappert H, Beuer F. Light transmittance by a multi-coloured zirconia material. Dent Mater J. 2015; 34:310-4.

29. Akar GC, Pekkan G, Cal E, Eskitaşçıoğlu G, Özcan M. Effects of surface-finishing protocols on the roughness, color change, and translucency of different ceramic systems. J Prosthet Dent. 2014; 112:314-21.

30. Kim HK, Kim SH, Lee JB, Ha SR. Effects of surface treatments on the translucency, opalescence, and surface texture of dental monolithic zirconia ceramics. J Prosthet Dent. 2016; 115:773-9.

31. Capa N, Celebi C, Casur A, Tuncel I, Usumez A. The translucency effect of different colored resin cements used with zirconia core and titanium abutments. Niger J Clin Pract. 2017; 20:1517-21.

32. Carames J, Tovar Suinaga L, Yu YC, Pérez A, Kang M. Clinical advantages and limitations of monolithic zirconia restorations full arch implant supported reconstruction: Case Series. Int J Dent. 2015; 2015:392496. 
33. Dede DÖ, Armağanci A, Ceylan G, Celik E, Cankaya S, Yilmaz B. Influence of implant abutment material on the color of different ceramic crown systems. J Prosthet Dent. 2016; 116:764-9.

34. Rosentritt M, Rembs A, Behr M, Hahnel S, Preis V. In vitro performance of implant-supported monolithic zirconia crowns: Influence of patient-specific tooth-coloured abutments with titanium adhesive bases. J Dent. 2015; 43:839-45.

35. Chang J, Da Silva JD, Sakai M, Kristiansen J, Ishikawa-Nagai S. The optical effect of composite luting cement on all ceramic crowns. J Dent. 2009; 37:937-43.

36. Tabatabaian F, Shabani S, Namdari M, Sadeghpour K. Masking ability of a zirconia ceramic on composite resin substrate shades. Dent Res J (Isfahan). 2017; 14:389-94.

37. Tabatabaian F, Taghizade F, Namdari M. Effect of coping thickness and background type on the masking ability of a zirconia ceramic. J Prosthet Dent. 2018; 119:159-65.

38. Tabatabaian F. Color aspect of monolithic zirconia restorations: A review of the literature. J Prosthodont. 2019;28:276-87.

39. Tabatabaian F, Dalirani S, Namdari M. Effect of thickness of zirconia ceramic on its masking ability: An in vitro study. J Prosthodont. 2017. DOI: 10.1111/jopr.12625.

40. Tabatabaian F, Motamedi E, Sahabi M, Torabzadeh H, Namdari M. Effect of thickness of monolithic zirconia ceramic on final color. J Prosthet Dent. 2018; 120:257-62.

41. Alghazzawi TF. The effect of extended aging on the optical properties of different zirconia materials. J Prosthodont Res. $2017 ; 61: 305-14$

42. Camposilvan E, Leone R, Gremillard L, Sorrentino R, Zarone F, Ferrari M, Chevalier J. Aging resistance, mechanical properties and translucency of different yttria-stabilized zirconia ceramics for monolithic dental crown applications. Dent Mater. 2018; 34:879-90.

43. Fathy SM, El-Fallal AA, El-Negoly SA, El Bedawy AB. Translucency of monolithic and core zirconia after hydrothermal aging. Acta Biomater Odontol Scand. 2015;1:86-92.

44. Kim HK, Kim SH. Effect of hydrothermal aging on the optical properties of precolored dental monolithic zirconia ceramics. J Prosthet Dent. 2019; 121:676-682.

45. Putra A, Chung KH, Flinn BD, Kuykendall T, Zheng C, Harada K, Raigrodski AJ. Effect of hydrothermal treatment on light transmission of translucent zirconias. J Prosthet Dent. 2017; 118:422-9.

46. Walczak K, Meißner H, Range U, Sakkas A, Boening K, Wieckiewicz M, Konstantinidis I. Translucency of zirconia ceramics before and after artificial aging. J Prosthodont. 2019; 28:e319-e324.

47. Ilie N, Stawarczyk B. Quantification of the amount of light passing through zirconia: the effect of material shade, thickness, and curing conditions. J Dent. 2014; 42:684-90.

48. Erdelt K, Pinheiro Dias Engler ML, Beuer F, Güth JF, Liebermann A, Schweiger J. Computable translucency as a function of thickness in a multi-layered zirconia. J Prosthet Dent. 2019; 121:683-689. 
49. Weigl P, Sander A, Wu Y, Felber R, Lauer HC, Rosentritt M. In-vitro performance and fracture strength of thin monolithic zirconia crowns. J Adv Prosthodont. 2018; 10:79-84.

50. Gu XH. Kern M. Marginal discrepancies and leakage of all-ceramic crowns: influence of luting agents and aging conditions. Int J Prosthodont. 2003; 16:109-16.

51. Aboushelib MN, Dozic A, Liem JK. Influence of framework color and layering technique on the final color of zirconia veneered restorations. Quintessence Int. 2010; 41:e84-9.

52. Nam JY, Park MG. Effects of aqueous and acid-based coloring liquids on the hardness of zirconia restorations. J Prosthet Dent. $2017 ; 117: 662-8$.

53. Orhun E. The effect of coloring liquid dipping time on the fracture load and color of zirconia ceramics. J Adv Prosthodont. $2017 ; 9: 67-73$

54. Askari E, Flores P, Silva F. A particle swarm-based algorithm for optimization of multi-layered and graded dental ceramics. J Mech Behav Biomed Mater. 2018; 77:461-9.

55. Silva LHD, Lima E, Miranda RBP, Favero SS, Lohbauer U, Cesar PF. Dental ceramics: a review of new materials and processing methods. Braz Oral Res. 2017; 31:e58.

56. Spyropoulou PE, Giroux EC, Razzoog ME, Duff RE. Translucency of shaded zirconia core material. J Prosthet Dent. 2011; 105:304-7.

57. Janyavula S, Lawson N, Cakir D, Beck P, Ramp LC, Burgess JO. The wear of polished and glazed zirconia against enamel. J Prosthet Dent. 2013; 109:22-9.

58. Kontos L, Schille C, Schweizer E, Geis-Gerstorfer J. Influence of surface treatment on the wear of solid zirconia. Acta Odontol Scand. 2013; 71:482-7.

59. Passos SP, Torrealba Y, Major P, Linke B, Flores-Mir C, Nychka JA. In vitro wear behavior of zirconia opposing enamel: a systematic review. J Prosthodont. 2014; 23:593-601.

60. Rupawala A, Musani SI, Madanshetty P, Dugal R, Shah UD, Sheth EJ. A study on the wear of enamel caused by monolithic zirconia and the subsequent phase transformation compared to two other ceramic systems. J Indian Prosthodont Soc. 2017; 17:8-14.

61. Zurek AD, Alfaro MF, Wee AG, Yuan JC, Barao VA, Mathew MT, Sukotjo C. Wear characteristics and volume loss of CAD/CAM ceramic materials. J Prosthodont. 2019; 28:e510-e518.

62. Mohammadi-Bassir M, Babasafari M, Rezvani MB, Jamshidian M. Effect of coarse grinding, overglazing, and 2 polishing systems on the flexural strength, surface roughness, and phase transformation of yttrium-stabilized tetragonal zirconia. $\mathrm{J}$ Prosthet Dent. 2017; 118:658-65.

63. Ozer F, Naden A, Turp V, Mante F, Sen D, Blatz MB. Effect of thickness and surface modifications on flexural strength of monolithic zirconia. J Prosthet Dent. 2018; 119:987-93. 
64. Deville S, Chevalier J, Gremillard L. Influence of surface finish and residual stresses on the ageing sensitivity of biomedical grade zirconia. Biomaterials. 2006; 27:2186-92.

65. Denry IL, Peacock JJ, Holloway JA. Effect of heat treatment after accelerated aging on phase transformation in 3Y-TZP. J Biomed Mater Res B Appl Biomater. 2010; 93:236-43.

66. Pop-Ciutrila IS, Ghinea R, Colosi HA, Dudea D. Dentin translucency and color evaluation in human incisors, canines, and molars. J Prosthet Dent. 2016; 115:475-81.

67. Church TD, Jessup JP, Guillory VL, Vandewalle KS. Translucency and strength of high-translucency monolithic zirconium oxide materials. Gen Dent. 2017; 65:48-52.

68. Jirajariyavej B, Wanapirom P, Anunmana C. Influence of implant abutment material and ceramic thickness on optical properties. J Prosthet Dent. 2018; 119:819-25.

69. Alqahtani MQ, Aljurais RM, Alshaafi MM. The effects of different shades of resin luting cement on the color of ceramic veneers. Dent Mater J. 2012; 31:354-61.

70. Calgaro PA, Furuse AY, Correr GM, Ornaghi BP, Gonzaga CC. Post-cementation colorimetric evaluation of the interaction between the thickness of ceramic veneers and the shade of resin cement. Am J Dent. 2014; 27:191-4.

71. Jankar AS, Kale Y, Pustake S, Bijjaragi S, Pustake B. Spectrophotometric study of the effect of luting agents on the resultant shade of ceramic veneers: An invitro study. J Clin Diagn Res. 2015; 9:ZC56-60.

72. Dede DÖ, Armaganci A, Ceylan G, Cankaya S, Celik E. Influence of abutment material and luting cements color on the final color of all ceramics. Acta Odontol Scand. 2013; 71:1570-8.

73. Lughi V, Sergo V. Low temperature degradation-aging-of zirconia: A critical review of the relevant aspects in dentistry. Dent Mater. 2010; 26:807-20.

74. Kelly JR, Denry I. Stabilized zirconia as a structural ceramic: an overview. Dent Mater. 2008; 24:289-98.

75. Nakamura K, Harada A, Kanno T, Inagaki R, Niwano Y, Milleding P, Örtengren U. The influence of low-temperature degradation and cyclic loading on the fracture resistance of monolithic zirconia molar crowns. J Mech Behav Biomed Mater. 2015; 47:49-56.

76. Balzaretti NM, da Jornada JA. Pressure dependence of the refractive index of monoclinic and yttria-stabilized cubic zirconia. Phys Rev B Condens Matter. 1995; 52:9266-9.

77. French RH, Glass SJ, Ohuchi FS, Xu Y, Ching WY. Experimental and theoretical determination of the electronic structure and optical properties of three phases of $\mathrm{ZrO}_{2}$. Phys Rev B Condens Matter. 1994; 49:5133-42. 